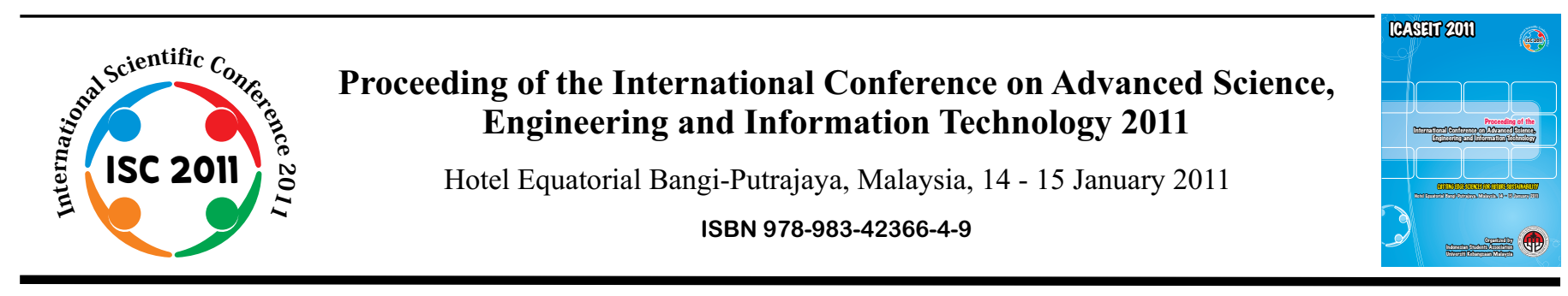

\title{
The Effect of Temporal EEG Signals While Listening to Quran Recitation
}

\author{
Azian Azamimi Abdullah" and Zainab Omar \\ \# School of Mechatronic Engineering \\ Universiti Malaysia Perlis (UniMAP), Kampus Ulu Pauh, 02600 Arau, Perlis, Malaysia \\ Tel.:+(6)04-9885328, E-mail:azamimi@unimap.edu.my
}

\begin{abstract}
Human brain which is one of the most complex organic systems, involves billons of interacting physiological and chemical process that will give rise to experimentally observed neuroelectrical activity, which is called an electroencephalogram (EEG). Many researchers have investigated the effect of various events to the EEG signals such as meditation and classical music [1]-[3]. From their analysis result, they claimed that meditation and classical music can help a person to be in relaxing conditions. This study is performed in order to extend the research findings of the effect of religious activities to the human brain. EEG signals from subject at rests, as well as in different cognitive states; listening to Quran recitation and listening to hard music are measured and analysed. Statistical analysis using SPSS software is performed in order to test the validity of obtained data. The analysis results from this study show that listening to Quran recitation can generate alpha wave and can help a person always in relax condition compared with listening to hard rock music.
\end{abstract}

Keywords - EEG, Quran Recitation, Alpha Wave

\section{INTRODUCTION}

The human brain is the center of the human nervous system and is a highly complex organ. Enclosed in the cranium, it has the same general structure as the brains of other mammals, but is over three times as large as the brain of a typical mammal with an equivalent body size [4]. The cerebral cortex is nearly symmetric in outward form, with left and right hemispheres. Anatomists conventionally divide each hemisphere into four "lobes", the frontal lobe, parietal lobe, temporal lobe, and occipital lobe. Brain electrical activities can be recorded by using Electroencephalogram (EEG). The signals consist of five types of waves. Those types of wave are delta, theta, alpha, beta and gamma wave [5]. For this study, the EEG wave will be detected while the subjects hear the Quran recitation. Basic alpha waves, which originate in the cortex, can be recorded if the subject closes his eyes and puts his brain "at rest" as much as possible during the recitation. This study aims to generate EEG wave during Quran recitation using EEG and find out the effect of temporal lobes of brain while listening to Quran recitation and hard rock music.
Alpha waves are one type of brain waves detected by electroencephalography (EEG) and predominantly originate from the occipital lobe during wakeful relaxation with closed eyes. Alpha waves are reduced with open eyes and drowsiness and sleep. They are thought to represent the activity of the visual cortex in an idle state. Occipital alpha waves during periods of eyes closed are the strongest EEG brain signals. They usually can be detected with the naked eye. An alpha-like variant called mu $(\mu)$ can be found over the motor cortex (central scalp) that is reduced with movement, or the intention to move. Alpha waves do not start to appear until three years of age [6].

On the other hand, beta wave varying within the range of $13 \mathrm{~Hz}$ to $30 \mathrm{~Hz}$. Beta wave is the usual waking rhythm of the brain associated with active thinking, intention or solving concrete problems. Normally it is found in normal adult. Rhythmical beta activity is encountered chiefly over the frontal and central region. The amplitude is normally under $30 \mu \mathrm{V}$ and less than $20 \mu \mathrm{Vpp}$.

This study is performed to see the effect of temporal EEG signals while listening to Quran recitation. In order to strengthen the findings, hard rock music is compared to the Quran recitation. 


\section{EXPERIMENTAL SETUP}

In this study, the EEG signals from about 14 subjects are captured. The appropriate electrode for this research is Ag$\mathrm{AgCl}$ surface electrodes and applied with electrode paste. The electrodes will be placed at the scalp with the 10-20 system electrode placements [7], but before placing the electrodes, the electrode placement area using EEG abrasive skin prepping gel must be swept. The experiment was conducted at room temperature with air-conditioning. The room environment was under soundproof. Subjects will be instructed to sit as their own comfortable. Then, subject has been instructed to listen to a piece of Quran recitation for three minutes using headphone. Periods of EEGs at rest with eyes closed were recorded before and after task. The duration was 30 seconds for each rest. The subject's eyes were closed while listening to the Quran recitation.
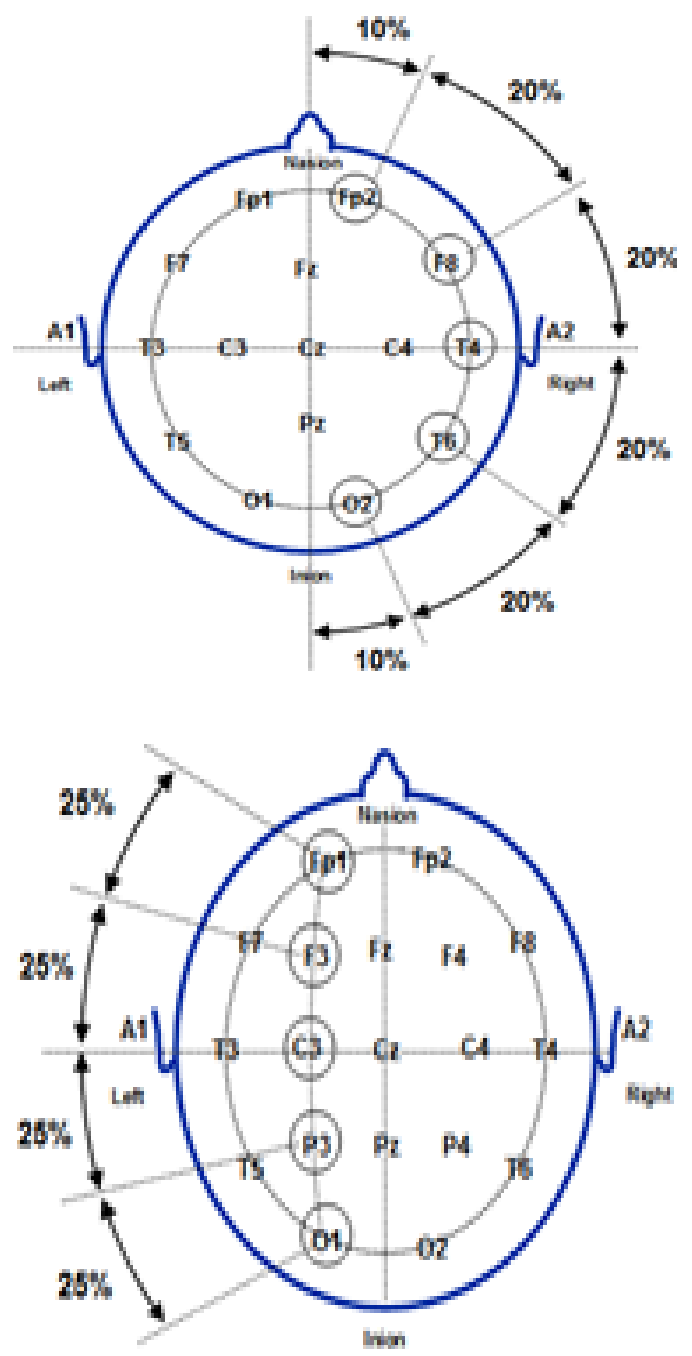

Fig. 1 10-20 Electrode placements.

The second stage of this experiment involves with another tasks to the subjects. The tasks given were listening to Quran recitation and hard music. The subjects conducted same as the previous procedure. Subjects instructed to sit as their own comfortable. Then, subject has been instructed to listen to a piece of Quran recitation for three minutes using headphone and listen to a piece of hard music for another three minutes after rest. Periods of EEGs at rest with eyes closed were recorded before, between and after each task. Their duration was one minute as each rest. The subject's eyes were closed while listening to the Quran recitation and hard music.

\section{A. Hardware}

This research used ProFusion EEG 4 v4.1 for the data collection. The E-Series EEG/PSG System is a device used to collect and store a patient's EEG and polysomnographic (PSG) signals, which are then used as an aid in the diagnosis of neurological and/or respiratory and respiratory related sleep disorders by qualified neurologists or physicians. The system is comprised of a number of hardware and software modules, which have been designed to provide up to 44 separate user-definable patient data input to record and replay patient data. The electrodes used to acquire patient data are connected between the patient and a Patient Interface Box, which is in turn connected to a Control Module. Then the next steps was selecting configuration and montage sequence by select the initial montage sequence and select the initial electrode assignment. These configurations are remembered. Then, to begin just click create study button. A study can be created without entering any Patient Details. The study will be created as an Anonymous study, and can be identified by the date and time that the recording is started. This is particularly valuable if a recording needs to be commenced quickly.

Impedance testing is an important tool for checking the viability of each electrode. Impedances should routinely be checked as part of the testing process, and can be performed before or during recording.

\section{B. Software}

Managing studies is performed using either Profusion Study Manager, or Compumedics neXus. Profusion EEG4 has a separate application also called Study Manager. There are four different types of Brain Mapping views are available. The types are:

- Brain Map

- Brain Map Cartoon

- Spectrum Map

- Coherence Map

Brain mapping is the current term used for the methodology of representing the EEG activity, either spontaneous or evoked, in the spatial domain as a topographic map projected onto the scalp. The feature represented may be amplitude of a given peak, a spectral variable, or a correlation measure. In essence, an EEG feature is extracted for all derivations at a given time sample, and a contour map of the distribution of the corresponding values over the scalp is constructed.

\section{Statistical Analysis}

Statistical analysis for this study is performed using the SPSS software. The t-test correlation, descriptive statistics and analysis of variance (ANOVA) have been used. It is important to test for a statistical significance of difference in original data. Statistics is considered by some to be a mathematical science pertaining to the collection, analysis, 
interpretation or explanation, and presentation of data, while others consider it to be a branch of mathematics concerned with collecting and interpreting data [8].

\section{RESULTS AND DISCUSSIONS}

\section{A. First Stage Experimental Result}

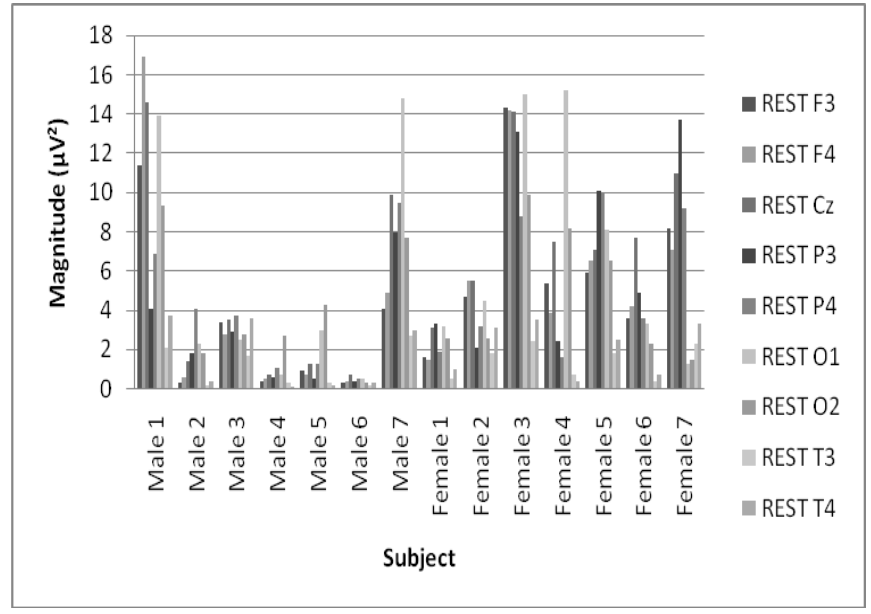

Fig. 2 Alpha wave magnitude for electrode $F 3, F 4, C z, P 3, P 4, O 1, O 2, T 3$ and T4 in coherence map during rest.

Figure 2 shows the magnitude of alpha wave for selected electrode during rest condition. The electrodes were chosen because of the electrodes positions that are similar to generate alpha wave of electrical activity in human brain. 14 subjects were conducted to complete the four minutes of experiment to obtain their brain electrical activities. The highest magnitude for alpha wave is achieving $17 \mu \mathrm{V}^{2}$ during rest.

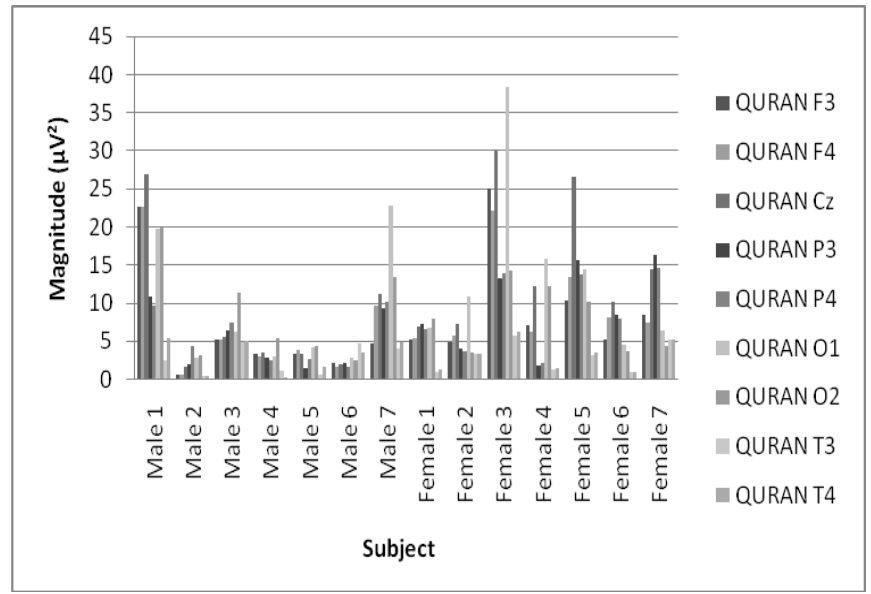

Fig. 3 Alpha wave magnitude for electrode $F 3, F 4, C z, P 3, P 4, O 1, O 2, T 3$ and $T 4$ in coherence map during Quran recitation.

Figure 3 shows the magnitude of alpha wave for selected electrode during Quran recitation condition. The highest magnitude was achieved more than $35 \mu \mathrm{V}^{2}$. Then, it can be compared by the previous graph that the both magnitude that obtain from the coherence map. The Alpha wave magnitude for electrode $\mathrm{F} 3, \mathrm{~F} 4, \mathrm{Cz}, \mathrm{P} 3, \mathrm{P} 4, \mathrm{O} 1, \mathrm{O} 2, \mathrm{~T} 3$ and $\mathrm{T} 4$ in coherence map during Quran recitation are higher than magnitude gain from rest condition.

\section{B. Second Stage Experimental Result}

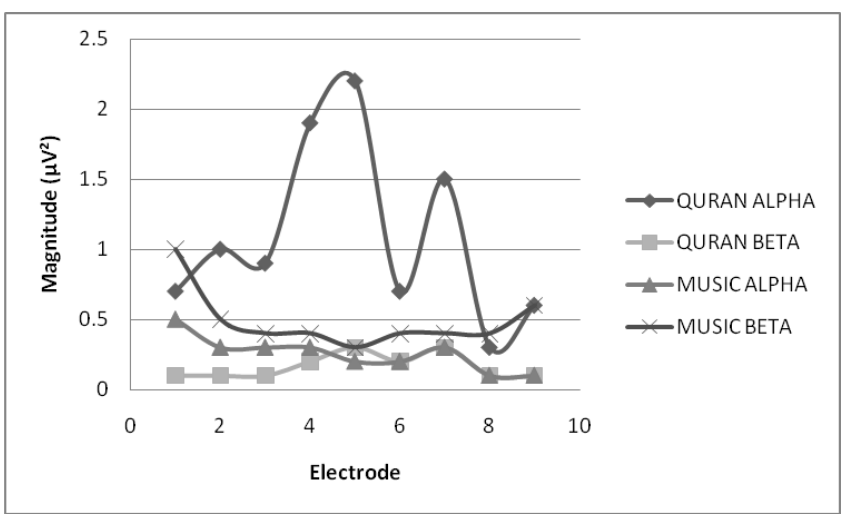

Fig. 4 Subject's A magnitude versus electrodes graph during listening Quran recitation and hard music.

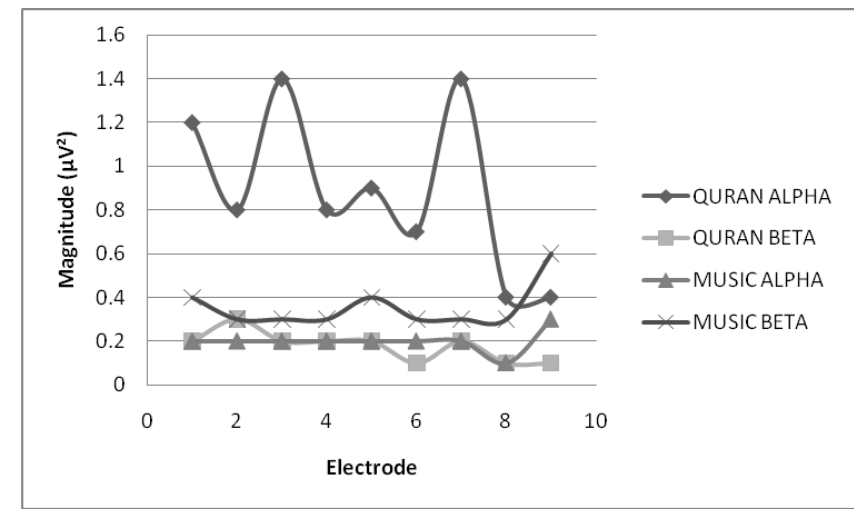

Fig. 5 Subject's B magnitude versus electrodes graph during listening Quran recitation and hard music.

For Figure 4 and 5, the electrode number represent by 1 (electrode F3), 2 (electrode F4), 3 (electrode Cz), 4 (electrode P3), 5 (electrode P4), 6 (electrode O1), 7 (electrode O2), 8 (electrode T3) and 9 (electrode T4). The higher of the beta value compared to the alpha wave value make the condition of the both subjects' shows that they were in the excited condition and not in the calmness condition during the listening to hard music task. However, the difference shows that during the listening to Quran recitation, both subjects were in the calm situation, with the increase of alpha wave magnitude value compared to beta value.

\section{Statistical Analysis Result}

The F-test of two samples for variance of subject A and B during listening to Quran recitation and hard music shows that subject's significant value ( $\mathrm{P}$ value) is below 0.05 $(\mathrm{P}<0.05)$. The obtained data are independent value as shown in Table 1-4. 
TABLE 1

F-TEST FOR VARIANCES OF SUBJECT A DURING LISTENING TO QURAN RECITATION

\begin{tabular}{lrr}
\hline & Variable 1 & Variable 2 \\
\hline Mean & 1.27142857 & 0.18571429 \\
Variance & 0.36238095 & 0.00809524 \\
Observations & 7 & 7 \\
df & 6 & 6 \\
$F$ & 44.7647059 & \\
$P(F<=f)$ one-tail & 0.00010094 & \\
F Critical one- & & \\
tail & 4.28386571 & \\
\hline
\end{tabular}

TABLE 2

F-TEST FOR VARIANCES OF SUBJECT B DURING LISTENING TO QURAN RECITATION

\begin{tabular}{lrr}
\hline & Variable & Variable \\
& \multicolumn{1}{c}{1} & \multicolumn{1}{c}{2} \\
\hline Mean & 1.028571 & 0.2 \\
Variance & 0.089048 & 0.003333 \\
Observations & 7 & 7 \\
df & 6 & 6 \\
F & 26.71429 & \\
P(F<=f) one-tail & 0.000445 & \\
F Critical one- & & \\
tail & 4.283866 & \\
\hline
\end{tabular}

TABLE 3

F-TEST FOR VARIANCES OF SUBJECT A DURING LISTENING TO HARD MUSIC

\begin{tabular}{lrr}
\hline & $\begin{array}{c}\text { Variable } \\
1\end{array}$ & $\begin{array}{c}\text { Variable } \\
\text { Mean }\end{array}$ \\
\hline Variance & 0.3 & 0.485714 \\
Observations & 0.01 & 0.054762 \\
df & 7 & 7 \\
F & 6 & 6 \\
P(F<=f) one-tail & 0.028816 & \\
F Critical one- & & \\
tail & 0.233434 & \\
\hline
\end{tabular}

TABLE 4

F-TEST FOR VARIANCES OF SUBJECT B DURING LISTENING TO HARD MUSIC

\begin{tabular}{lrr}
\hline & Variable & Variable \\
& \multicolumn{1}{c}{1} & \multicolumn{1}{c}{2} \\
\hline Mean & 0.2 & 0.328571 \\
Variance & $8.99 \mathrm{E}-34$ & 0.002381 \\
Observations & 7 & 7 \\
df & 6 & 6 \\
F & $3.77 \mathrm{E}-31$ & \\
P(F<=f) one-tail & 0 & \\
F Critical one- & \multicolumn{2}{|}{} \\
tail & 0.233434 \\
\hline
\end{tabular}

\section{CONCLUSIONS}

Alpha waves are one type of brain waves detected by EEG and predominantly originate from the occipital lobe during wakeful relaxation with closed eyes. Alpha waves are reduced with open eyes and drowsiness and sleep. They are thought to represent the activity of the visual cortex in an idle state. Occipital alpha waves during periods of eyes closed are the strongest EEG brain signals. The alpha wave magnitude during listening to Quran recitation is higher compared to rest condition and listening to hard music. In listening to Quran recitation and hard music experiment, the beta wave is appeared; in that case, known that during listening to hard music, human can get excited and make the beta wave appear. There are difficulties such as the appearance of artifacts. The artifact will have to be filtered to get the smooth signals. The study proved that human can feel relax and calm during listening to Quran recitation compared to the rest condition and listening to hard music.

\section{REFERENCES}

[1] Bhattacharya, J. \& Petsche, H. 2001 Universality in the brain while listening to music, 2425-2426.

[2] Banquet, J. P. Spectral Analysis of the EEG in Meditation, Electroencephalography and Clinical Neurophysiology. 1973, 35:P143-151.

[3] Nakamura, S., Sadato, N., Oohashi, T., Nishina, E., Fuwamoto, Y. Yonekura, Y., 1999 Analysis of music-brain interaction with simultaneous measurement of regional cerebral blood flow and electroencephalogram beta rhythm in human subjects, 1-5.

[4] Daly D, Pedley T, eds. Current Practice of Clinical Electroencephalography. $2^{\text {nd }} \mathrm{ed}$. New York: Raven Press; 1990.

[5] Johanson, D. C. (1996). From Lucy to language. New York: Simon and Schuster, p. 80 .

[6] Kolev V, Başar-Eroglu C, Aksu F, Başar E. (1994). EEG rhythmicities evoked by visual stimuli in three-year-old children. Int J Neurosci. 75(3-4):257-70.

[7] Fachner, J. \& Rittner, S. (2004) Sound and trance in a ritualistic setting visualised with EEG Brainmapping. Music Therapy Today. Vol. V, Issue 2.

[8] SPSS Software Version 17. 